\title{
Influence of Pregnancy-Related Conditions on Human Epididymis Protein 4 Serum Levels in Comparison to CA 125 - a Prospective Cohort Trial
}

\section{Auswirkungen von schwangerschaftsbedingten Erkrankungen auf den humanen Epididymis-Protein-4-Spiegel im Blut verglichen mit CA 125 - eine prospektive Kohortenstudie}

(c) $(1) \Theta$

Authors

Samira Abdel Azim ${ }^{1}$, Irene Mutz-Dehbalaie ${ }^{1}$, Verena Wieser ${ }^{1}$, Astrid Berger ${ }^{1}$, Bettina Böttcher ${ }^{2}$, Heidi Fiegl ${ }^{3}$, Christian Marth ${ }^{1}$, Andreas Widschwendter ${ }^{1}$

Affiliations

1 Department of Obstetrics and Gynecology, Medical University of Innsbruck, Innsbruck, Austria

2 Department of Gynecological Endocrinology and Reproductive Medicine, Medical University of Innsbruck, Innsbruck, Austria

3 Department of Gynecology and Obstetrics, Laboratory for Clinical Biochemistry, Medical University of Innsbruck, Innsbruck, Austria

\section{Key words}

HE4, CA 125, pregnancy, tumor marker, biomarker, adnexal mass

\section{Schlüsselwörter}

HE4, CA 125, Schwangerschaft, Tumormarker, Biomarker, Adnextumor

\section{received}

11. 12.2020

accepted after revision

5.4. 2021

Bibliography

Geburtsh Frauenheilk 2021; 81: 1047-1054

DOI 10.1055/a-1475-4296

ISSN 0016-5751

(C) 2021. The Author(s).

This is an open access article published by Thieme under the terms of the Creative Commons Attribution-NonDerivative-NonCommercial-License, permitting copying and reproduction so long as the original work is given appropriate credit. Contents may not be used for commercial purposes, or adapted, remixed, transformed or built upon. (https://creativecommons.org/licenses/by-nc-nd/4.0/)

Georg Thieme Verlag KG, Rüdigerstraße 14,

70469 Stuttgart, Germany
Correspondence

Irene Mutz-Dehbalaie, MD

Department of Obstetrics and Gynecology,

Medical University of Innsbruck

Anichstrasse 35, 6020 Innsbruck, Austria

irene.mutz-dehbalaie@i-med.ac.at

$\Theta$

Supplementary material is available under

https://doi.org/10.1055/a-1475-4296

\section{ABSTRACT}

Introduction HE4 and CA 125, two established biomarkers for assessing adnexal masses in non-pregnant women, are hardly investigated in pregnancy, especially in pregnancy-associated conditions. The aim was to evaluate HE4 and CA 125 levels in the course of pregnancy and to assess the impact of pregnancy disorders, contractions and rupture of membranes on HE4 and CA 125 serum levels in order to use these parameters for evaluation of adnexal masses in pregnancy.

Patients and Methods Blood samples ( $n=238$ ) of 201 women seen at the Medical University of Innsbruck, Austria, were prospectively obtained during pregnancy and postpartum. Serum concentrations of HE4 and CA 125 were analyzed. ROMA index was calculated by the premenopausal formula.

Results HE4 serum levels were highest in the third trimester. Contractions $(p<0.001)$, rupture of membranes $(p=0.005)$ and pregnancy-associated diseases $(p=0.003)$ were associated with higher HE4 levels. As much as $97.5 \%$ of HE4 measurements remained below the recommended cut-off for premenopausal women $(70 \mathrm{pmol} / \mathrm{l})$. CA 125 levels were not altered by pregnancy-associated conditions. Generally, CA 125 exhibited a wider serum level variability, exceeding the established cut-off of $35 \mathrm{U} / \mathrm{ml}$ in $16.4 \%$. 
Conclusions HE4 serum levels are influenced by several pregnancy-related conditions leading to significantly higher levels in these cases. Despite differing medians according to trimester, the 95th percentile cut-offs and almost all maximum values during the entire course of pregnancy were below the established cut-off for premenopausal women. It was also superior to the performance of ROMA index. Therefore, HE4 can be used as a valuable negative predictive marker for the assessment of adnexal masses during pregnancy.

\section{ZUSAMMENFASSUNG}

Einleitung Die Änderungen von HE4 and CA 125, 2 etablierten Biomarkern für die Evaluierung von Adnextumoren in nicht schwangeren Frauen, wurden bislang kaum während der Schwangerschaft untersucht, vor allem nicht im Zusammenhang mit schwangerschaftsbedingten Erkrankungen. Ziel dieser Studie war es, den HE4- und CA-125-Serumspiegel im Verlauf der Schwangerschaft zu messen und die Auswirkungen von schwangerschaftsbedingten Erkrankungen, Wehentätigkeit und Blasensprung auf die HE4- und CA-125-Serumspiegel auszuwerten, um diese Parameter für die Evaluierung von Adnexbefunden während der Schwangerschaft einzusetzen.

Patienten und Methoden Von 201 Frauen, die an der Medizinischen Universität Innsbruck, Österreich vorstellig waren, wurden Blutproben $(n=238)$ prospektiv während der Schwangerschaft sowie nach der Entbindung entnommen.
Die Serumkonzentrationen von HE4 und CA 125 wurden ausgewertet. Der jeweilige ROMA-Index wurde anhand der prämenopausalen Formel kalkuliert.

Ergebnisse Die höchsten Werte des HE4-Serumspiegels wurden im 3. Trimenon gemessen. Wehentätigkeit $(p<0,001)$, Blasensprung $(p=0,005)$ und schwangerschaftsbedingte Erkrankungen $(p=0,003)$ waren ebenfalls mit höheren HE4Werte assoziiert. Fast 97,5\% der gemessenen HE4-Werte blieben aber unter dem empfohlenen Cut-off-Wert für prämenopausale Frauen $(70 \mathrm{pmol} / \mathrm{l})$. Schwangerschaftsbedingte Erkrankungen hatten keine Auswirkung auf die Höhe der CA-125-Werte. Die Variabilität der Serumwerte war aber für CA-125-Werte größer, und bei 16,4\% der Patientinnen wurde der etablierte Cut-off-Wert von $35 \mathrm{U} / \mathrm{ml}$ überschritten.

Schlussfolgerungen Mehrere schwangerschaftsbedingte Erkrankungen wirkten sich auf die HE4-Serumwerte aus, und die Serumwerte waren bei diesen Patientinnen signifikant erhöht. Obwohl sich die Medianwerte je nach Trimenon unterschieden, blieben die Cut-off-Werte des 95. Perzentils sowie fast alle Maximalwerte während der gesamten Schwangerschaftsdauer unter den etablierten Cut-off-Werten für prämenopausale Frauen. Die Leistungsfähigkeit dieser Werte übertraf sogar die Aussagekraft des ROMA-Indexes. Damit stellen HE4-Werte einen nützlichen negativen prädiktiven Marker bei der Einschätzung von Adnexbefunden während der Schwangerschaft dar.

\section{Introduction}

Adnexal masses in pregnancy are a rare finding but present a challenge for physicians regarding clinical approach and management. They are usually discovered as an incidental finding during antenatal ultrasound screening. According to literature, adnexal masses are diagnosed in 1 to $10 \%$ of all pregnant women [1-3] of which 2 to $6 \%$ classify as malignant $[1,4,5]$. Guidelines on how to approach affected pregnant women are not established. Therefore, recommendations remain vague.

In non-pregnant women with adnexal masses, tumor markers are often assessed to distinguish between benign and malignant conditions. CA 125 (Cancer Antigen 125) is the gold standard biomarker for epithelial ovarian cancer and plays an important role, not only in diagnostic but also in prognostic assessment and therapy monitoring [6,7]. Data on the effect of pregnancy on CA 125 levels are conflicting. Several studies have shown elevated marker concentrations at least at some point in pregnancy [8], thereby giving rise to the assumption that CA 125 is of limited diagnostic use in pregnancy. Other biomarkers, such as alfa-feto protein or $\beta$-hCG (human chorionic gonadotropin), that are routinely used to stratify germ cell malignancies are of limited value as pregnancy itself may influence levels [3].

Human epididymis protein 4 (HE4), has recently emerged as a new diagnostic and prognostic marker in ovarian and endometrial cancer $[9,10]$. HE4 exhibits good sensitivity and superior specificity compared to CA 125 . This was especially observed in pre- menopausal women, and it is less elevated in women with benign diseases [11].

ROMA (risk of Ovarian malignancy algorithm) is an index that combines the quantitative values of HE4, CA 125 and menopausal state in an algorithm to assess the risk for ovarian cancer. It was initially developed to improve the prediction compared to either marker alone [12].

Seven studies have investigated HE4 serum levels in pregnant women [13-19]. All of these studies only investigated healthy pregnant women, one group additionally looked at HE4 serum levels in cases of threatened first trimester miscarriage [16] and another investigated the ROMA index [15]. The results of these studies are partly conflicting as some authors report no difference in HE4 levels in pregnancy [17] or even lower levels than in premenopausal women [13] whereas others confirmed higher HE4 levels with advancing gestation $[16,19]$. To date, no studies have been published to evaluate interferences of HE4 and CA 125 levels with regard to pregnancy-related conditions and postpartum.

The aim of this study was to evaluate HE4 serum levels in comparison to CA 125 levels in serum samples collected prospectively during pregnancy and after delivery. We also investigated the effect of contractions, rupture of membranes, pregnancy-associated diseases and delivery on HE4 serum levels. Additionally, we analyzed the performance of ROMA index compared to individual marker values alone. 


\section{Material and Methods}

\section{Study population}

Blood samples ( $n=238$ ) were prospectively collected from a convenient cohort of 201 pregnant women, who presented at the Department of Obstetrics and Gynecology, Medical University of Innsbruck as part of routine prenatal care. The study was approved by the Ethics Committee of the Medical University of Innsbruck (reference number AN 4102; 292/417). Informed written consent was obtained from each woman included in this study. Exclusion criteria were age under 18 years, a history of cancer and active cancer.

We have used the three trimesters as defined timepoints for biomarker measurements. Trimesters were defined as first trimester (weeks 0-14), second trimester (weeks 15-26) and third trimester (from 27 weeks until delivery). Serum samples were obtained from 4 to 42 weeks of gestation and within three hours after delivery. In 20 out of 201 women two serum samples were available and in eight patients three or more serum samples were obtained. Ten serum samples were taken within three hours postpartum. Patient characteristics of the study population are depicted in $>$ Table 1.

Of all participating women $33(16.4 \%)$ presented with contractions (i.e. preterm labor) or onset of labor and 27 (13.4\%) with rupture of membranes at the time of blood sampling.
Observed pregnancy-associated conditions were diabetes ( $n=8,4.0 \%$ ), hypertension ( $n=8,4.0 \%)$, HELLP syndrome (hemolysis, elevated liver enzymes, low platelets) ( $n=3,1.5 \%$ ), preeclampsia $(n=5,2.5 \%)$ and fetal pathologies comprising hydrops ( $n=8,4.0 \%)$ and trisomy $(n=4,2.0 \%)$.

We divided our study population into two subgroups: In order to obtain normal values for HE4 and CA 125 a subgroup of 125 women with neither pregnancy-associated conditions, fetal abnormalities, rupture of membranes nor contractions was formed, referred to as subgroup 1.

Subgroup 2 contained all women with rupture of membranes or contractions and included all cases of pregnancy-associated pathologies and eight cases of hydrops/trisomy.

\section{Serum assays}

Blood samples were taken during antenatal care visits. Serum was stored at $-50^{\circ} \mathrm{C}$ until analysis. Specimens were analyzed by means of chemiluminescent microparticle immunoassays specific for CA 125 (ARCHITECT CA 125 II assay) or for HE4 (ARCHITECT HE4 assay; both Abbott $\mathrm{GmbH}$, Wiesbaden, Germany) using the ARCHITECT i2000SR Immunoassay Analyzer [11].

\section{ROMA Index}

ROMA index was determined by the logistic regression formula for premenopausal patients with the measured CA 125 and HE4 levels in the following algorithm: First the predictive index was calcu-

- Table 1 Patient characteristics.

\begin{tabular}{|c|c|c|c|c|c|c|}
\hline \multirow[b]{2}{*}{ Variable } & \multicolumn{2}{|c|}{ All women $(n=201)$} & \multicolumn{2}{|c|}{ Subgroup $1(n=125)$} & \multicolumn{2}{|c|}{ Subgroup $2(n=76)$} \\
\hline & Median & Range & Median & Range & Median & Range \\
\hline Age & 30.9 & $18.3-44.8$ & 30.8 & $18.3-41.7$ & 30.4 & $18.6-44.8$ \\
\hline $\operatorname{BMI}\left(\mathrm{kg} / \mathrm{m}^{2}\right)$ & 25.7 & $16-45$ & 24.9 & $16-45$ & 26.3 & $19-41$ \\
\hline HE4 (pmol/l) & 36 & $17-144$ & 31 & $17-76$ & 43 & $20-114$ \\
\hline \multirow[t]{2}{*}{ CA $125(\mathrm{U} / \mathrm{ml})$} & 22 & $3-524$ & 21 & $5-180$ & 23.5 & $3-524$ \\
\hline & $\mathbf{n}$ & $\%$ & $\mathrm{n}$ & $\%$ & $\mathrm{n}$ & $\%$ \\
\hline 1st trimester & 56 & 27.9 & 49 & 39.2 & 7 & 9.2 \\
\hline 2nd trimester & 19 & 9.5 & 17 & 13.6 & 2 & 2.6 \\
\hline 3rd trimester & 126 & 62.7 & 59 & 47.2 & 67 & 88.2 \\
\hline Twin pregnancy & $13^{*}$ & 6.5 & $10^{*}$ & 76.9 & $3^{*}$ & 23.1 \\
\hline Diabetes & 8 & 4.0 & & & 8 & 10.5 \\
\hline Hypertension & 8 & 4.0 & & & 8 & 10.5 \\
\hline HELLP & 3 & 1.5 & & & 3 & 3.9 \\
\hline Preeclampsia & 5 & 2.5 & & & 5 & 6.6 \\
\hline Hydrops & 8 & 4.0 & & & 8 & 10.5 \\
\hline Trisomy & 4 & 2.0 & & & 4 & 5.3 \\
\hline Contractions & 33 & 16.4 & & & 33 & 43.4 \\
\hline Rupture of membranes & 27 & 13.4 & & & 27 & 35.5 \\
\hline \multicolumn{7}{|c|}{ HELLP: hemolysis, elevated liver enzymes, low platelets. } \\
\hline \multicolumn{7}{|c|}{ Subgroup 1: All healthy women without rupture of membranes or contractions. } \\
\hline \multicolumn{7}{|c|}{ Subgroup 2: Women with rupture of membranes and/or contractions, pregnancy-associated diseases and/or fetal anomalies. } \\
\hline
\end{tabular}



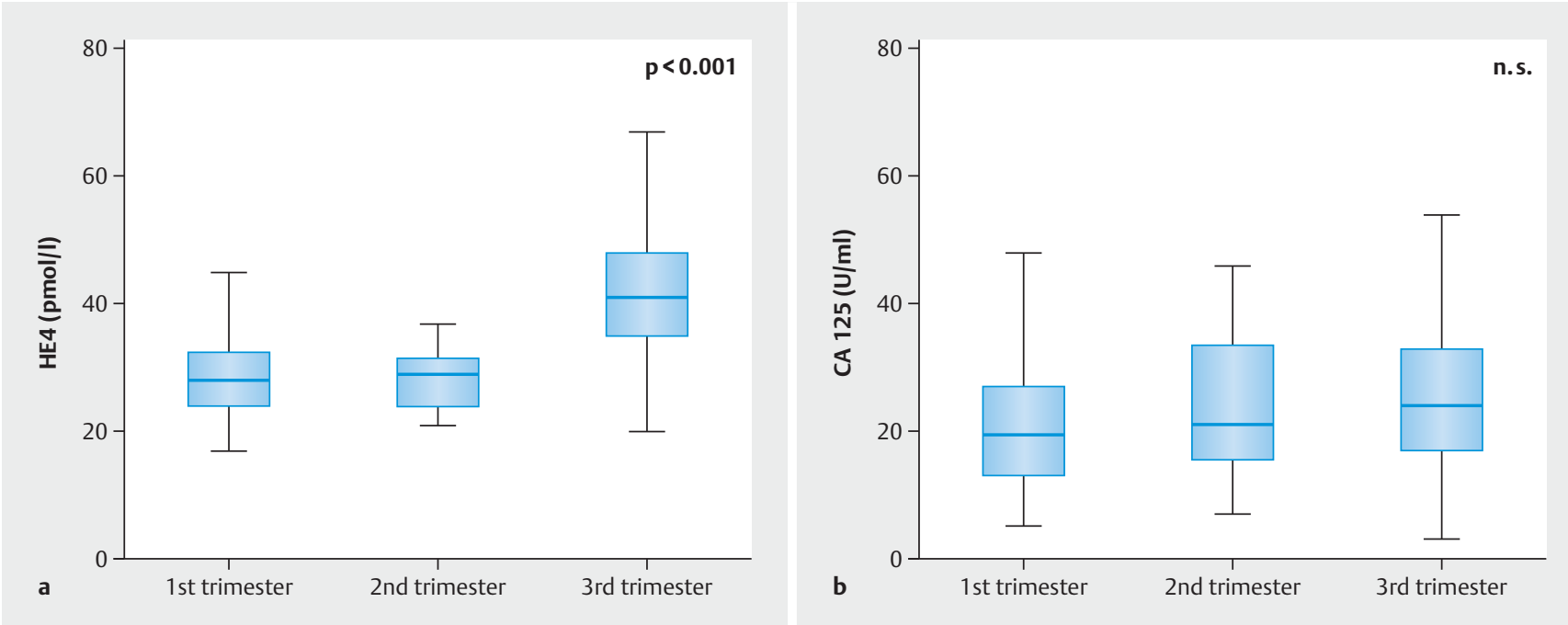

- Fig. 1 Serum levels of HE4 (a) and CA 125 (b) by trimester for all samples.

lated by: $-12+2.38 \times$ LN (HE4) $+0.0626 \times$ LN (CA 125). Then the predicted probability (ROMA index) was computed as follows: ROMA value $(\%)=\frac{e^{p t}}{\left(1+e^{p t}\right)} \times 100$ [12]. ROMA values $<7.4 \%$ or $\geq 7.4 \%$ were used to discriminate low risk and high risk results for premenopausal women [20].

\section{Statistics}

Differences between marker concentrations according to variables were tested with the Mann-Whitney $U$ test and the KruskalWallis test. A probability of $<0.05$ was considered statistically significant. These statistical calculations were performed, and all figures created with SPSS, version 25.0.

\section{Results}

\section{HE4 and CA 125 levels over the course of pregnancy}

Distribution of HE4 according to trimesters was significantly different $(p<0.001)$ in all women $(n=201)$ and also in the group without pathologies or ruptured membranes/contractions $(n=125)$. HE4 levels rose significantly when measured longitudinally. Levels in the third trimester were significantly higher than in the first and second trimester (trimester 1 vs. 3 and trimester 2 vs. 3 : $p<0.001$; Fig. 1 a). In contrast CA 125 levels showed no differences in distribution throughout gestation ( $\vee$ Fig. $\mathbf{1} \mathbf{b}$ ).

Blood was drawn twice during pregnancy from 20 (10.0\%) pregnant women, three times from eight women. The median time between the first and second and the first and third sampling was four and three weeks, respectively. Of the 238 blood samples ten were taken postpartum. Compared with sera of all pregnant women, considerably higher HE4 as well as CA 125 levels were noted after delivery (HE4, p<0.001; CA 125, p<0.001).

\section{Range of marker levels}

Median HE4 serum levels of all samples were 36 pmol/I (range 17$114 \mathrm{pmol} / \mathrm{l}$ ), and median CA 125 levels were $22 \mathrm{U} / \mathrm{ml}$ (range 3$524 \mathrm{U} / \mathrm{ml}$ ). ROMA index performance was satisfactory in the $1 \mathrm{st}$ and 2 nd trimester but showed a higher proportion of high-risk results in the 3rd trimester ( $\triangleright$ Table 2 ). First and third trimester values at the 95th percentile for HE4 were 43 and $61 \mathrm{pmol} / \mathrm{I}$ and for CA 125 values were 47 and $45 \mathrm{U} / \mathrm{ml}$, respectively. Five serum samples $(2.5 \%)$ exceeded the HE4 cut-off (>70 pmol/l), and 33 samples (16.4\%) exceeded the CA 125 cut-off (> $35 \mathrm{U} / \mathrm{ml})$ as demonstrated in $>$ Fig. 2.

- Table 2 Median HE4 and CA 125 levels and ROMA Index according to trimesters.

\begin{tabular}{|c|c|c|c|c|c|c|}
\hline \multirow[t]{2}{*}{ Variable } & \multicolumn{2}{|c|}{ HE4 (pmol/I) } & \multicolumn{2}{|c|}{ CA 125 (U/ml) } & \multirow{2}{*}{$\begin{array}{l}\text { ROMA Index } \\
<7.4 \%\end{array}$} & \multirow[b]{2}{*}{$>7.4 \%$} \\
\hline & Median & Range & Median & Range & & \\
\hline All samples & 36 & $17-114$ & 22 & $3-524$ & $171(85.1 \%)$ & $30(14.9 \%)$ \\
\hline 1st trimester & 28 & $17-51$ & 19.5 & $5-55$ & 55 (98.2\%) & $1(1.8 \%)$ \\
\hline 2nd trimester & 29 & $21-37$ & 21 & $7-524$ & $19(100 \%)$ & $0(0 \%)$ \\
\hline 3rd trimester & 41 & $20-114$ & 24 & $3-152$ & 97 (77\%) & $29(23 \%)$ \\
\hline
\end{tabular}



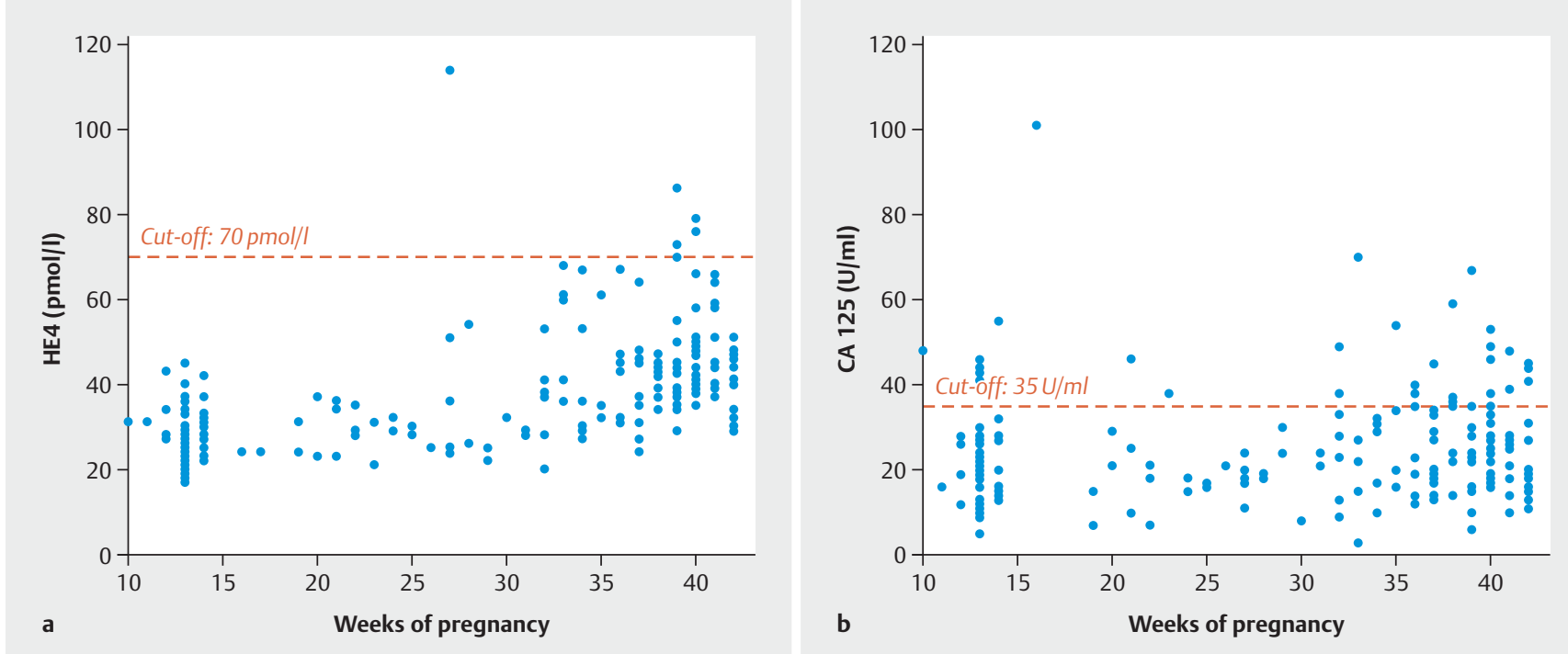

- Fig. 2 Dot blot diagrams demonstrating HE4 levels (a) and CA 125 levels (b) with respective cut-offs (dashed horizontal lines) over the course of pregnancy.
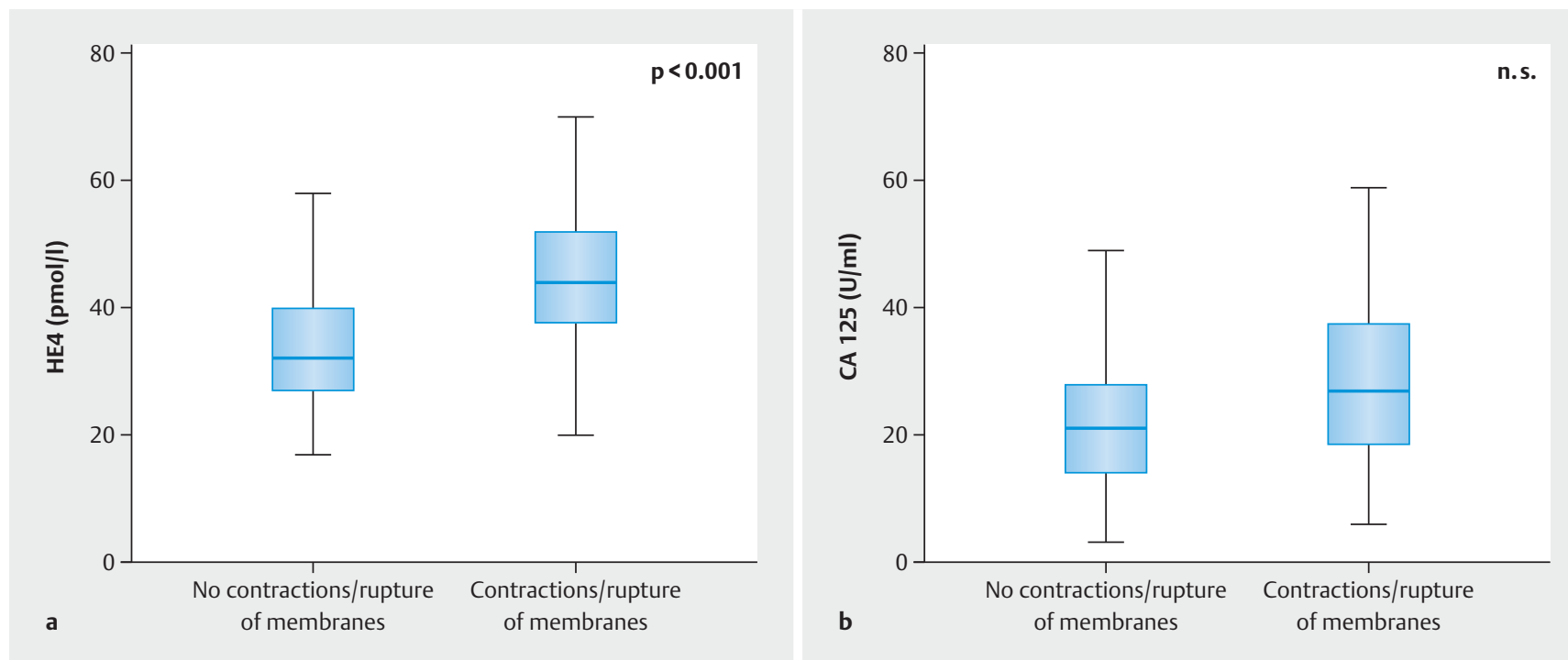

- Fig. 3 HE4 (a) and CA 125 (b) serum levels of women with and without contractions and/or rupture of membranes.

\section{Analyses in subgroups}

In subgroup 1 (which included all healthy pregnant women, i.e. women without rupture of membranes, contractions, pregnancy-associated pathologies or cases of hydrops/trisomy) the median value for HE4 was $31 \mathrm{pmol} / \mathrm{l}$ (range $17-76 \mathrm{pmol} / \mathrm{l}$ ) at a 95th percentile of $51 \mathrm{pmol} / \mathrm{l}$ and the median value for CA 125 was $21 \mathrm{U} / \mathrm{ml}$ (range $5-180 \mathrm{U} / \mathrm{ml}$ ) with a 95 th percentile of $46 \mathrm{U} /$ $\mathrm{ml}$.

Age was divided into three categories (18-29, 30-39, $\geq 40$ ) and was not associated with differences between HE4 and CA 125 levels. Importantly, women with twin pregnancies ( $n=13,6.5 \%$ ) showed no differences in HE4 or CA 125 marker lev- els compared to women with singleton pregnancies (HE4 $\mathrm{p}=0.499$; CA $125 \mathrm{p}=0.442$ ). Median HE4 was $35 \mathrm{pmol} / \mathrm{l}$ (range 23-67) and median CA 125 level was 20 U/ml (range 10-101). We therefore included uneventful twin pregnancies $(n=10)$ in subgroup 1 and those with a pathologic condition $(n=3)$ (i.e. hypertension, hydrops) in subgroup 2.

Thirty-three (16.4\%) samples were obtained from women with contractions, eight women presented in labor and 27 samples (13.4\%) were obtained from women after spontaneous rupture of membranes (SROM). HE4 serum levels in these women were markedly higher $(p<0.001)$ than levels in healthy pregnant wom- 

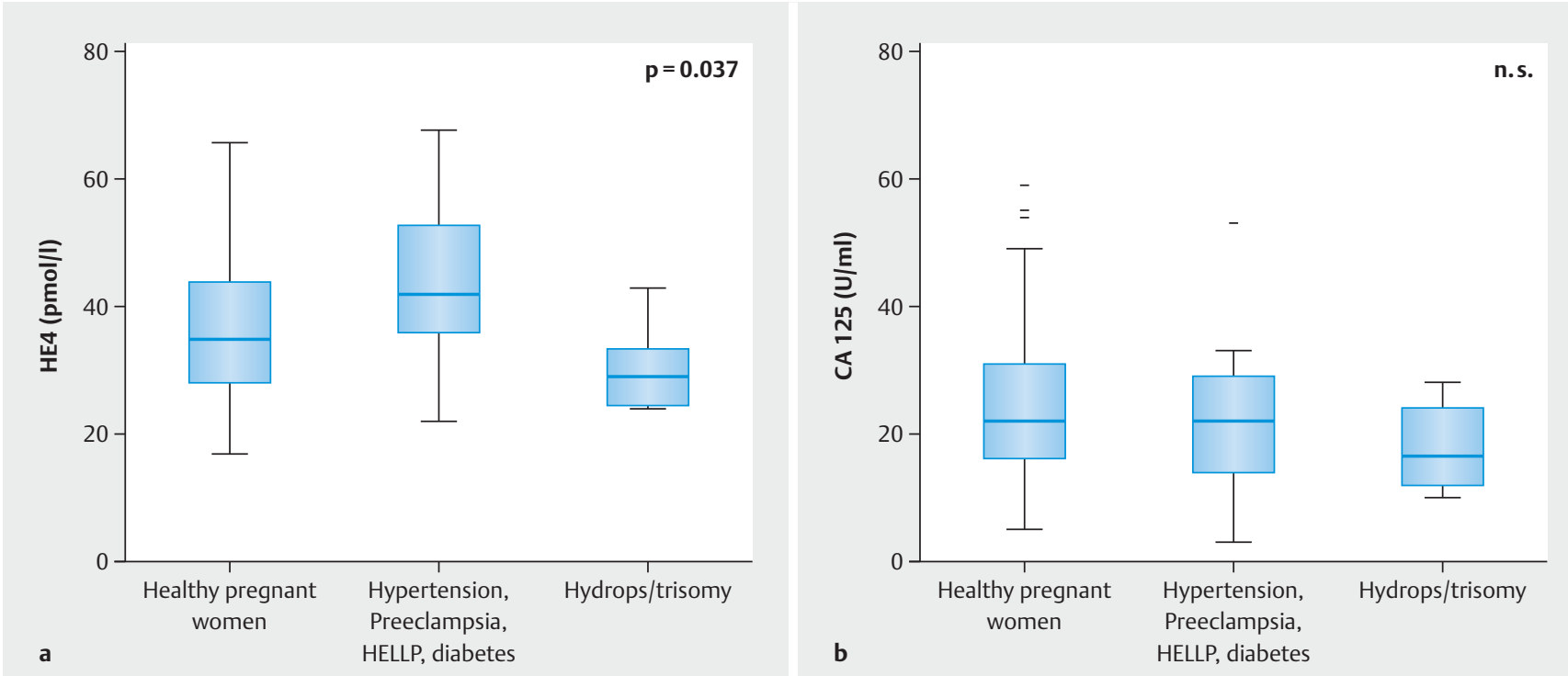

- Fig. 4 HE4 (a) and CA 125 serum levels (b) in women with various pregnancy-associated conditions compared to healthy pregnant women.

en (subgroup 1). However, no difference was seen in CA 125 levels among these women ( $\bullet$ Fig. $\mathbf{3} \mathbf{a}$ and $\mathbf{b}$ ).

When assessing only sera of women in the third trimester $(n=126)$ HE4 levels remained significantly elevated in women with ruptured membranes or contractions as compared to CA 125 ( $p<0.001$ vs. $p=0.145)$, see supplemental Fig. S1.

HE4 levels were higher in sera of women with pregnancy-associated conditions than in healthy pregnant women $(n=125)$ $(p=0.037)$. When dichotomizing women with pathologies like hypertension, HELLP, preeclampsia and diabetes $(n=23 ; 11.4 \%)$ and those with hydrops and/or chromosomal anomaly ( $n=9 ; 4.7 \%$ ), the effect persisted only in the first group $(p=0.003)(\nabla$ Fig. 4 a). However, CA 125 levels did not differ when comparing the two pathology groups and healthy pregnant women ( Fig. 4 b).

\section{Discussion}

Although HE4 plays a potent role in the discrimination of adnexal masses, data concerning its reliability in pregnancy are limited. Seven studies with a combined total of 1504 women reported on HE4 levels in pregnancy [13-19]. Except for one group [16], who investigated the effect of threatened miscarriage on HE4 levels, none of the studies took into account interference of serum HE4 levels and any particular pregnancy-associated conditions. Lu et al. [15] additionally evaluated ROMA index in pregnancy.

To our knowledge, this is the first study on the effect of pregnancy-associated conditions on HE4 and CA 125 serum levels.

In premenopausal women, where CA 125 is of limited value in detecting ovarian cancer due to its low specificity, HE4 is especially appreciated $[11,21]$. HE4 exhibits the most compelling benefit in early stages of ovarian cancer with higher sensitivity in comparison to CA 125 [22].

In our study CA 125 median values showed no difference when comparing the individual trimesters ( $\triangleright$ Fig. 1). However, despite stable median values, our data demonstrate rather wide ranges of CA 125 ( $\triangleright$ Table 1 ).

A review of tumor markers in pregnancy including ten publications [8] found elevated CA 125 levels in up to $35 \%$ of all measurements. Levels were predominately higher in the first trimester, decreasing to stable median values below the cut-off in the second and third trimester. This is in accordance with the data of the aforementioned studies. A possible reason for the discrepancy between higher first trimester levels reported by previous studies and our results might be that most of our first trimester specimens were collected at the time of first trimester screening at 12 to 13 weeks of gestation. At this point CA 125 levels may already be decreasing. In a study by Park et al. [14], CA 125 levels in the pregnant cohort did not exceed the established cut-off by reaching a maximum level of $30.7 \mathrm{U} / \mathrm{ml}$, although they were more than $50 \%$ higher than those in the non-pregnant group.

Our data on HE4 distribution according to trimester show significantly higher median levels in the third compared to the first and second trimester $(p<0.001$; $>$ Fig. 1). This was shown for each subgroup. Investigation of longitudinally collected sera of our population showed significantly higher levels with advancing gestational age. The results are in line with those of Lu et al. [15] who reported increasing median HE4 concentrations with each trimester. Moore et al. [13] identified no differences in median HE4 levels by trimester, but showed significant differences in the distribution of HE4 levels. According to trimesters our 95th percentile cut-offs reach from 43.8 to $61.0 \mathrm{pmol} / \mathrm{l}$, and the 95 th percentile cut-off for all included pregnant women in our study was $51 \mathrm{pmol} / \mathrm{l}$. They do not markedly differ from those reported by Moore et al. (35.1 to $50.2 \mathrm{pmol} / \mathrm{l}$ and $49.6 \mathrm{pmol} / \mathrm{l}$, respectively) [13]. It has to be mentioned that Moore et al. [11] and Park et al. [23] used the HE4 EIA kit by Fujirebio (Fujirebio Diagnostics Inc. Malvern, PA) with a 95th percentile cut-off for premenopausal women of $89.1 \mathrm{pmol} / \mathrm{l}$. Ruggeri et al. have confirmed a similar per- 
formance of the two assays [24]. Lu et al. determined HE4 by Elecsys HE4 Kit (Roche) with a cut-off of 65.8 pmol/l.

Park et al. [23] reported the 95th percentile cut-offs for HE4 of 29.7 to $30.3 \mathrm{pmol} / \mathrm{l}$ in healthy individuals. They did not determine cut-offs for pregnant women but mentioned that median levels were not higher than $7 \mathrm{pmol} / \mathrm{l}$ as compared to the non-pregnant population. It is noteworthy that in the population of Lu et al. [15] $23.3 \%$ of HE4 measurements in the third trimester were beyond the premenopausal cut-off level (for Chinese women) of $65.8 \mathrm{pmol} / \mathrm{l}$.

In contrast to the above-mentioned studies, we evaluated HE4 distribution according to certain conditions related to pregnancy. Thirty-three (16.4\%) of our specimens were obtained from women having contractions and during labor. HE4 serum levels in these women were markedly higher $(p<0.001)$, whereas no difference was seen in CA 125 levels $(p=0.053)$. Similarly, HE4 levels in samples obtained from women after rupture of membranes were significantly higher $(p=0.045)$, whereas CA 125 was not altered $(p=0.636)$ ( $\vee$ Fig. 2). To avoid bias due to marker distribution according to trimester, analyses were performed only in women in the third trimester.

Pathologic conditions investigated in this study include hypertension, HELLP, preeclampsia and diabetes, as well as fetal hydrops and fetal trisomy. Marker levels according to pathologic findings were evaluated in subgroup 2.

Pregnancy-related diseases (hypertension, HELLP, preeclampsia and diabetes) were associated with significantly higher HE4 levels $(p=0.003)$ than levels in healthy pregnant women. In case of fetal hydrops and trisomy HE4 serum levels were not increased ( $\triangleright$ Fig. 3a). The underlying mechanism might be a decreased glomerular filtration rate (GFR), since all the above-mentioned conditions are accompanied by restricted renal function. GFR is known to be reduced by 30 to $40 \%$ in preeclampsia [25]. Hypertension and diabetes are not merely risk factors for (pre-)eclampsia but are also precursor states. Additionally, renal impairment is also a known factor in these conditions. Nagy et al. [26] described the impact of reduced GFR on renal HE4 clearance. Higher creatinine levels in patients with impaired renal function were shown to be associated with higher HE4 serum levels [27]. Compared with all sera of pregnant women, considerably higher HE4 as well as CA 125 levels were noted postpartum (HE4 p<0.001, CA 125 $p<0.001$ ); for CA 125 this has already been reported [28]. It remains unclear to what extent placental factors may contribute to these phenomena as well as to higher serum levels in labor and after rupture of membranes.

This study of HE4 levels in pregnancy is the first to evaluate serum levels throughout the course of pregnancy and to simultaneously assess potential interference from pregnancy-associated conditions. Unfortunately, only limited data were available on adnexal masses in our study population. Further studies are needed to address this issue. Another limitation of our study is the small number of longitudinal measurements, because only few women in our study attended full antenatal care at our institution. Contractions, rupture of membranes and the pregnancy-associated diseases as hypertension, HELLP, preeclampsia and diabetes were seen to be associated with significantly higher HE4 levels. CA 125 levels were not influenced by these conditions. Generally, CA 125 exhibited a wider range, exceeding the established cut-off of $35 \mathrm{U} / \mathrm{ml}$ in 33 samples (16.4\%), whereas HE4 maximum values remained below the recommended cut-off for premenopausal women of $70 \mathrm{pmol} / \mathrm{l}$, in $97.5 \%$ of cases.

ROMA index performance was satisfactory in the 1st and 2nd trimester but showed a higher proportion of high-risk results in the 3rd trimester. This fact can mainly be attributed to the great range of CA 125 especially towards the end of pregnancy. ROMA index performed better when only patients with the absence of pathological and pregnancy-related conditions were analyzed. In this group a high-risk result was only obtained in $6.4 \%$ of cases. Although ROMA index was initially introduced to improve the risk prediction compared to either marker alone, we could not confirm this result in our cohort of pregnant women. CA 125 was the least reliable factor followed by ROMA index. HE4 performance was superior to the latter to two. Our observations are in line with previously published data by Lu et al. [15]. They also found that ROMA index values in the third trimester are of smaller clinical significance, due to the wide range of CA 125.

\section{Conclusion}

Based on its stable levels HE4 appears to be a valuable and reliable biomarker for the diagnosis of adnexal masses in pregnancy. However, when HE4 serum levels are measured longitudinally throughout pregnancy to monitor adnexal masses, pregnancyrelated changes in HE4 levels such as rupture of membranes, contractions and pregnancy-associated diseases must be taken into account. Cut-off values for HE4 in pregnancy should be implemented.

\section{Funding}

ARCHITECT CA 125 and HE4 assays were kindly provided by Abbott $\mathrm{GmbH}$, Wiesbaden, Germany.

\section{Ethical Standards}

The study was approved by the Ethics Committee of the Medical University of Innsbruck (reference number AN 4102; 292/417) and has been performed in accordance with the ethical standards laid down in the 1964 Declaration of Helsinki and its later amendments.

Informed written consent was obtained from each woman included in this study.

\section{Acknowledgements}

We would like to acknowledge Andrea Sapinsky for her administrative support.

Conflict of Interest

The authors declare that they have no conflict of interest. 


\section{References}

[1] Amant F, Brepoels L, Halaska MJ et al. Gynaecologic cancer complicating pregnancy: an overview. Best Pract Res Clin Obstet Gynaecol 2010; 24 : $61-79$

[2] Bernhard LM, Klebba PK, Gray DL et al. Predictors of persistence of adnexal masses in pregnancy. Obstet Gynecol 1999; 93: 585-589

[3] Schwartz N, Timor-Tritsch IE, Wang E. Adnexal masses in pregnancy. Clin Obstet Gynecol 2009; 52: 570-585

[4] Behtash N, Karimi Zarchi M, Modares Gilani M et al. Ovarian carcinoma associated with pregnancy: a clinicopathologic analysis of 23 cases and review of the literature. BMC Pregnancy Childbirth 2008; 8: 3

[5] Leiserowitz GS, Xing G, Cress R et al. Adnexal masses in pregnancy: how often are they malignant? Gynecol Oncol 2006; 101: 315-321

[6] Chan KKL, Chen C-A, Nam J-H et al. The use of HE4 in the prediction of ovarian cancer in Asian women with a pelvic mass. Gynecol Oncol 2013; 128: $239-244$

[7] Schummer M, Drescher C, Forrest R et al. Evaluation of ovarian cancer remission markers HE4, MMP7 and Mesothelin by comparison to the established marker CA125. Gynecol Oncol 2012; 125: 65-69

[8] Han SN, Lotgerink A, Gziri MM et al. Physiologic variations of serum tumor markers in gynecological malignancies during pregnancy: a systematic review. BMC Med 2012; 10: 86

[9] Mutz-Dehbalaie I, Egle D, Fessler S et al. HE4 is an independent prognostic marker in endometrial cancer patients. Gynecol Oncol 2012; 126: 186-191

[10] Simmons AR, Baggerly K, Bast RC. The emerging role of HE4 in the evaluation of epithelial ovarian and endometrial carcinomas. Oncology (Williston Park, NY) 2013; 27: 548-556

[11] Moore RG, Miller MC, Steinhoff MM et al. Serum HE4 levels are less frequently elevated than CA125 in women with benign gynecologic disorders. Am J Obstet Gynecol 2012; 206: 351.e1-351.e8

[12] Moore RG, McMeekin DS, Brown AK et al. A novel multiple marker bioassay utilizing HE4 and CA125 for the prediction of ovarian cancer in patients with a pelvic mass. Gynecol Oncol 2009; 112: 40-46

[13] Moore RG, Miller MC, Eklund EE et al. Serum levels of the ovarian cancer biomarker HE4 are decreased in pregnancy and increase with age. Am J Obstet Gynecol 2012; 206: 349.e1-349.e7

[14] Park Y, Kim Y, Lee EY et al. Reference ranges for HE4 and CA125 in a large Asian population by automated assays and diagnostic performances for ovarian cancer. Int J Cancer 2012; 130: 1136-1144
[15] Lu J, Zheng Z, Zhang Q et al. Measurement of HE4 and CA125 and establishment of reference intervals for the ROMA index in the sera of pregnant women. J Clin Lab Anal 2018; 32: e22368

[16] Wang Z, Zhou F, Xiao X et al. Serum levels of human epididymis protein 4 are more stable than cancer antigen 125 in early and mid-term pregnancy. J Obstet Gynaecol Res 2018; 44: 2053-2058

[17] Gucer F, Kiran G, Canaz E et al. Serum human epididymis protein 4 can be a useful tumor marker in the differential diagnosis of adnexal masses during pregnancy: a pilot study. Eur J Gynaecol Oncol 2015; 36: 406-409

[18] Uslu B, Dogan S, Özdem S et al. Serum concentrations of HE4 and Ca125 in uncomplicated pregnancies: a longitudinal study. J Obstet Gynaecol 2020; 40: 70-76

[19] Gasiorowska E, Kluz T, Lipski D et al. Human Epididymis Protein 4 (HE4) Reference Limits in Polish Population of Healthy Women, Pregnant Women, and Women with Benign Ovarian Tumors. Dis Markers 2019; 2019: 3890906

[20] Dakubo GD. Cancer Biomarkers in Body Fluids. Cham: Springer International Publishing; 2017

[21] Molina R, Escudero JM, Augé JM et al. HE4 a novel tumour marker for ovarian cancer: comparison with CA 125 and ROMA algorithm in patients with gynaecological diseases. Tumour Biol 2011; 32: 1087-1095

[22] Havrilesky LI, Whitehead CM, Rubatt JM et al. Evaluation of biomarker panels for early stage ovarian cancer detection and monitoring for disease recurrence. Gynecol Oncol 2008; 110: 374-382

[23] Park Y, Lee J-H, Hong DJ et al. Diagnostic performances of HE4 and CA125 for the detection of ovarian cancer from patients with various gynecologic and non-gynecologic diseases. Clin Biochem 2011; 44: 884-888

[24] Ruggeri G, Bandiera E, Zanotti L et al. HE4 and epithelial ovarian cancer: comparison and clinical evaluation of two immunoassays and a combination algorithm. Clin Chim Acta 2011; 412: 1447-1453

[25] Lafayette RA, Druzin M, Sibley R et al. Nature of glomerular dysfunction in pre-eclampsia. Kidney Int 1998; 54: 1240-1249

[26] Nagy B, Krasznai ZT, Balla $\mathrm{H}$ et al. Elevated human epididymis protein 4 concentrations in chronic kidney disease. Ann Clin Biochem 2012; 49: $377-380$

[27] Bolstad N, Øijordsbakken M, Nustad K et al. Human epididymis protein 4 reference limits and natural variation in a Nordic reference population. Tumour Biol 2012; 33: 141-148

[28] Spitzer M, Kaushal N, Benjamin F. Maternal CA-125 levels in pregnancy and the puerperium. J Reprod Med 1998; 43: 387-392 